\title{
Robot-assisted ureteroureterostomy in pediatric patients: current perspectives
}

This article was published in the following Dove Press journal:

Robotic Surgery: Research and Reviews

24 April 2017

Number of times this article has been viewed

\author{
Jonathan S Ellison \\ Thomas S Lendvay \\ Division of Pediatric Urology, Seattle \\ Children's Hospital, University of \\ Washington, Seattle, WA, USA
}

\begin{abstract}
Developments in pediatric robotic surgery have increased the feasibility of minimally invasive surgery for complex urinary tract reconstruction. Ureteroureterostomy is a commonly employed strategy for the management of a duplicated ureteral system with either upper pole obstruction or lower pole vesicoureteral reflux, and this approach minimizes the risk to a healthy ureter as might be seen in a common sheath ureteral reimplant and avoids complex dissection around the renal hilum as with a heminephrectomy. The robotic platform enables optimum instrument manipulation for an end-to-side ureteral anastomosis as well as excellent visualization deep into the pelvis for excision of the distal ureteral stump. In this study, the indications and preoperative evaluation for pediatric robotic ureteroureterostomy (RUU) were described and intraoperative considerations for a successful repair were highlighted. In order to assess the outcomes, a PubMed search was performed to find the articles focusing on RUU in the pediatric population. The institutional experience of the authors was also reviewed. As with an open procedure, both minimizing dissection on the recipient ureter and ensuring a tension-free, watertight anastomosis are key principles to minimize complications. Although port placement is similar to that in robotic pyeloplasty, small adjustments may need to be made to ensure access to the pelvis. An assistant port and/or traction sutures is often used to aid in the dissection and anastomosis. RUU was first described in 2008, and several reports have demonstrated positive short-term results. However, median follow-up times are limited with most series reporting outcomes $<1$ year postoperatively. A future study is required to establish the long-term efficacy of this procedure and define the optimum patient population for a robotic approach.
\end{abstract}

Keywords: robotic surgical procedures, ureteral diseases, pediatrics

\section{Introduction}

Ureteral duplication may be found in up to $2 \%$ of the general population. Although the majority of ureteral duplications are uncomplicated and asymptomatic, up to $30 \%$ of patients with duplication may have evidence of renal disease. ${ }^{1}$ Embryologically, ureteral duplication occurs due to abnormal branching of the ureteric bud off the mesonephric duct. As described by Weigert and Meyer, so termed the Weigert-Meyer law, the upper pole ureter typically arises closer to the Wolffian duct, resulting in an upper pole ureteral orifice that migrates caudally and medially. Thus, the upper pole system is more commonly obstructed from this ectopic insertion and/or an associated ureterocele. Conversely, the lower pole system is often located more laterally, with a shorter intramural tunnel. This anatomy more often results in vesicoureteral reflux (VUR) to the lower pole system..$^{2-4}$
Correspondence: Jonathan S Ellison Department of Pediatric Urology, Seattle Children's Hospital, University of Washington, OA 9.220, 4800 Sand Point Way Seattle, WA 98105 , USA

$\mathrm{Tel}+\mathrm{I} 2069878248$

Fax +l 2069873835

Email jonathan.ellison@seattlechildrens. org 
Complications of ureteral duplication associated with ureteral ectopia include obstruction with a risk for recurrent urinary tract infection (UTI) or demise in renal function of the upper pole moiety. In women, ureteral ectopia can result in incontinence owing to abnormal insertion below the urinary sphincter within the urinary tract or into Mullerian structures, such as the vagina or uterus. Incontinence is not classically seen in boys with ureteral ectopia as the ectopic ureters are generally proximal to the external sphincter such as within Wolffian structures. ${ }^{5}$ Indications for intervention on the upper pole ureter in a duplicated system include progressive obstruction with a concern for future renal function, recurrent infections, pain, or incontinence. ${ }^{6,7}$ Meanwhile, symptomatic VUR of the lower pole system may present with recurrent febrile UTIs. ${ }^{8}$ Although some debates exist regarding the optimum approach for the upper urinary tract in a duplicated system, ipsilateral ureteroureterostomy is a safe and effective strategy to manage upper pole ureteral obstruction or reflux, and adoption of the robotic platform for this technique has shown promising early results. ${ }^{6,9-11}$ The objective of this study was to provide a narrative review on the evaluation and management of ureteral duplication as well as to discuss alternatives, technical considerations, and outcomes for robotic ureteroureterostomy (RUU).

\section{Methods}

In order to assess the outcomes of RUU in children, a PubMed search was performed for all the articles published within the past 10 years, including patients aged $<18$ years with $\mathrm{MeSH}$ terms of "ureterocele," "duplicated ureter," or "ureter" and "laparoscopic surgery". The abstracts were reviewed from a total of 115 articles. The articles not including ureteroureterostomy performed with a robotic platform were excluded. However, the articles including ureteroureterostomy for stricture, rather than pathologies associated with duplication, were included. A total of 5 articles were included for the assessment of outcomes of RUU. No Institutional Review Board (IRB) approval was required for the literature review.

The authors' institutional data were reviewed retrospectively, assessing all children undergoing RUU from 2009 to present. Indications, complications, and follow-up were captured by using an IRB-approved robotic database. No IRB approval was required for the literature review.

\section{Benefits of robotic-assisted surgery}

Although the history of robotic-assisted surgery spans back several decades, the widespread da Vincic system was introduced in 1999 and the first surgeries using this platform were described soon thereafter. ${ }^{12,13}$ Numerous applications of the robotic-assisted platform have been described in pediatric urology. ${ }^{14}$ This platform offers several advantages to conventional laparoscopy. Wristed instrumentation allows for expanded degrees of freedom, simplifying intracorporeal suturing and tissue manipulation. Visualization is improved with three-dimensional camera systems, enabling more accurate depth perception for the surgeon. In addition, positioning of the surgeon at the robotic console offers ergonomic surgeon benefit, which may improve surgeon fatigue for longer surgical cases. ${ }^{13}$

\section{Evaluation}

Evaluation of a child with a suspected clinically significant ureteral duplication should begin with a thorough history and physical examination. Antenatal history should focus on abnormal renal ultrasound findings or history of oligohydramnios. Ureteral duplication and ureteroceles account for $5 \%-7 \%$ of all causes of antenatal hydronephrosis; however, in the absence of significant bilateral disease, oligohydramnios would not be expected. ${ }^{15}$ A history of UTIs or unexplained fevers should be explored, including the presence of fevers during the UTI, a need for intravenous antibiotics, and organism type and antibiotic-resistance patterns. In older children, primary persistent incontinence may suggest ureteral ectopia in girls. These girls typically present with a life-long history of incontinence without any successful period of toilet training. The incontinence is typically persistent without any "dry" periods, day or night. Pain is not a typical presentation for chronic obstruction, and the character, location, and timing of pain should be carefully elucidated.

Physical examination is often normal in these children. Screening for hypertension is an important assessment when evaluating for renal health. Rarely, infants with a severe hydronephrotic segment may have a palpable mass; however, when present, it typically represents hydronephrosis from a nonduplicated ureteropelvic junction obstruction. A genitourinary examination in girls may reveal active urinary incontinence or even an ectopic ureteral orifice inserting in the distal vagina or Gartner's duct. The assessment of prior medical and health histories is important for surgical planning and risk assessment. Reoperative pediatric robotic surgery is feasible; however, prior abdominal surgeries may increase the risk of intraperitoneal adhesions, making laparoscopic surgery difficult, if not impossible. ${ }^{16,17}$

Imaging typically begins with a renal bladder ultrasound, which can reveal upper tract dilation and provide insight into the health of upper pole renal parenchyma. Furthermore, 
tracing the dilated ureter to the level of the bladder can demonstrate an ureterocele or give suggestion to ureteral ectopia as the dilated ureter extends beyond the bladder (Figure 1). Although an ultrasound may lack sensitivity to detect renal duplication in all cases, a diseased duplicated renal segment should easily be seen on standard ultrasonography. A nuclear medicine (NM) renogram can provide input as to upper pole function. This study could prove useful to provide baseline function. Renograms are also helpful if the functional potential of the upper pole moiety is in doubt and the surgeon is considering an extirpative procedure. However, routine NM renography may not be necessary to determine split polar function if this information did not influence the surgeon's reconstructive decisions. ${ }^{18}$ Voiding cystourethrography is important to evaluate for ipsilateral lower pole VUR as an upper to lower pole ureteroureterostomy is contraindicated in the setting of lower pole VUR unless the lower pole reflux is also addressed. ${ }^{6,9}$ Magnetic resonance imaging with urography (MRU) can provide additional, detailed anatomic assessment, though typically at the cost of a general anesthetic, particularly in young children. ${ }^{19}$ An MRU also has the ability to objectively assess split and absolute renal function. ${ }^{20}$ However, the authors found that, in most cases, US and NM renography can provide sufficient information for surgical decision-making, acknowledging that additional anatomic information can be gathered during cystoscopy and retrograde pyelography at the time of the planned procedure.

\section{Management strategies for obstructed upper pole segment in a duplicated system}

Wide surgeon variation exists for the management of duplicated systems, especially in the setting of an associated ureterocele. Many surgeons cite the preservation of renal function and prevention of future symptoms as contributing factors to decision-making. ${ }^{21}$ Observation can be considered for asymptomatic, nonobstructed ureteroceles in duplicated collecting systems. ${ }^{22}$ Ureterocele puncture is typically a first-line approach in very young or symptomatic children but has been associated with a high rate of further intervention, especially in ureteroceles associated with duplicated collecting systems. ${ }^{23,24}$ However, neither observational nor endoscopic approaches have been described for symptomatic ectopic ureters.

When surgical correction is considered, strategies can be divided into upper and lower urinary tract management. Lower tract management is typically accomplished with common sheath ureteral reimplantation. Such a strategy addresses the anatomical abnormality as distal as possible, "normalizing" anatomy. Managing the ureters within the common sheath may be more favorable to the distal ureteral blood supply of both ureters. However, common sheath reimplantation requires substantial mobilization of the lower pole ureter and may be unnecessary if the lower pole does not reflux. Furthermore, a true common sheath approach is not feasible with a widely ectopic upper pole ureter. ${ }^{25}$

Upper tract management strategies may be extirpative or reconstructive. Upper pole heminephrectomy has been advocated in order to remove a diseased renal segment that may be a source of hypertension or infection in the future. However, such an approach is technically challenging, especially when performed via minimally invasive techniques. Dissection around the renal hilum poses a risk to the lower pole moiety with up to $17 \%$ of patients showing decline in postoperative ipsilateral renal function and a $5 \%$ rate of complete or significant renal loss. ${ }^{26,27}$ In the select patients with a nonfunctioning upper pole and ureteral ectopia resulting in incontinence, selective ureteral clipping via a laparoscopic approach has been described. ${ }^{28}$

An alternative strategy that avoids dissection around the lower pole hilum is an upper to lower pole ureteroureterostomy. Such an approach has been described at the level of the renal pelvis as well as at the level of the pelvic brim, the
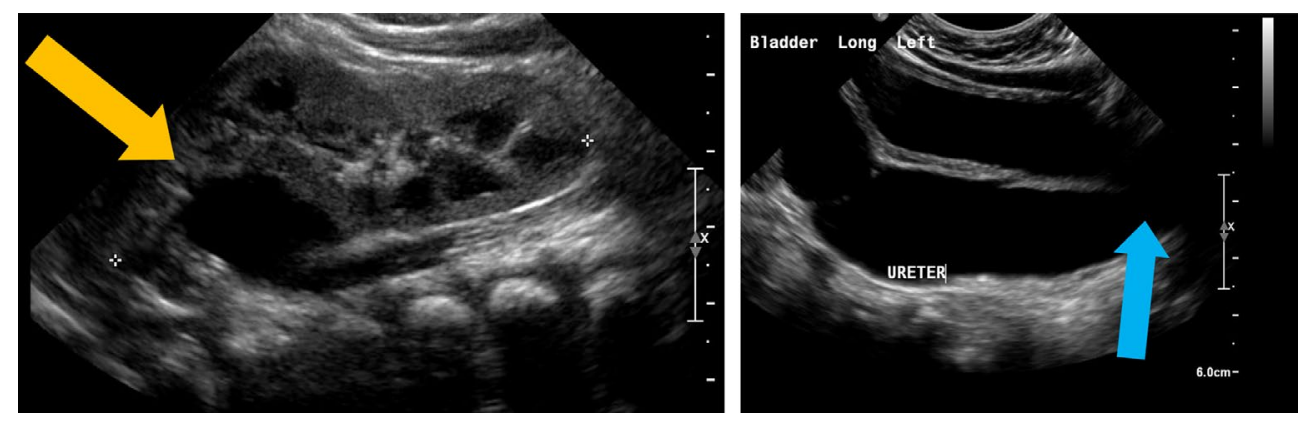

Figure I (Left) ultrasonographic images of a duplicated collecting system with upper pole hydronephrosis with parenchymal preservation marked by the orange arrow. (Right) images of the bladder and significantly dilated ureter extending distally beyond the bladder marked by the blue arrow. 
latter initially raising concerns regarding the so-called "yo-yo reflux" due to the iatrogenically created " $y$ " duplication. ${ }^{6,7} \mathrm{~A}$ number of series of ipsilateral ureteroureterostomy have been described with no concern for the yo-yo reflux phenomenon when performed more distally. ${ }^{69}$ At the risk of exposing the lower pole recipient ureter to additional harm, this strategy relieves the obstruction of the upper pole while minimizing risk to the upper pole renal parenchyma and negating the complications that may occur with lower tract management.

\section{Management strategies for reflux into a duplicated system}

If present, VUR will typically occur into the lower pole of a duplicated system. ${ }^{29}$ Ureteral duplication has been associated with lower rates of spontaneous resolution of VUR, although spontaneous resolution may still occur in these patients. ${ }^{30,31}$ However, there is no evidence to show a higher rate of breakthrough infections in this population. As such, initial management with prophylactic antibiotics is still warranted with indications for surgical intervention based on the failure of antibiotic prophylaxis. ${ }^{8}$

Subureteric injections of a bulking agent, such as dextranomer/hyaluronic acid, have been successfully used for VUR in duplicated systems, although the success rates may be lower than for nonduplicated systems. ${ }^{32,33}$ Ureteral reimplantation, as discussed above, often requires a common sheath approach with an inherent risk to the healthy ureter. ${ }^{25}$ As such, ipsilateral ureteroureterostomy, in this scenario anastomosing the refluxing lower pole ureter into the healthy upper pole system, has been successfully utilized for the management of VUR in the select cases..$^{29,34}$

\section{Surgical technique for robotic ureteroureterostomy}

When undertaking a robotic endeavor, it is important to develop institutional knowledge of the technology. ${ }^{35}$ This includes ensuring familiarity of the room setup for the anesthesiology team, operating room nurses, and surgical technicians. The patient must be positioned in the room in a way to allow robotic docking with consideration to lighting arrangements, visual monitors, anesthesia setup, and the sterile field.

General anesthesia with an endotracheal tube and muscle paralysis is necessary. An orogastric tube is placed to decompress stomach prior to port placement. The patient is first placed into lithotomy position for a cystoscopy, wherein a double coil stent is placed in the ipsilateral lower pole ureter. Although the stent can also be placed intracorporeally in an antegrade-retrograde fashion, the preplacement of the stent is less challenging and enables intraoperative identification of the recipient lower pole ureter, especially if the difference in ureteral dilation between the two ureters is minimal. Following cystoscopy, a Foley catheter is placed and the patient is positioned in a modified flank position with the side of surgical interest oriented upward. The patient is secured to the table, and all exposed pressure points are well padded. The surgeon must ensure no barriers, such as IV poles or anesthetic tubing, to robotic arm movement on the patient during positioning. Positioning is especially important as the surgeon will be at the console for the majority of the case, and following draping, identification of positional issues will become more difficult.

Although initial intraperitoneal access can be obtained with either a Veress or Hasson technique, ${ }^{36}$ a Hasson technique via the natural fascial opening at the umbilicus to allow the placement of an 8.5-mm camera port was preferred. Additional ports were then placed under direct vision superiorly and inferiorly at the midline. Often in smaller infants, the inferior port will be placed across the midline away from the site of interest in order to allow enough intracorporeal working space for the inferior robotic arm (Figure 2). Unlike in adults, $8 \mathrm{~cm}$ spacing between ports is not necessary to prevent robotic arm collisions. ${ }^{37}$ This is due to the smaller working space required in the surgical field, negating the necessity for wide arm movements extracorporeally. Furthermore, the pliability of the young child's belly affords a proportionally larger expansion of abdominal space upon distention, thereby creating more separation between ports once insufflated. Practically, it is often necessary due to the patient size to place these ports much closer together (Figure 2). Due to the laxity of the abdominal wall in pediatric patients, ports are often pulled upward, or "burped," to provide additional working space during robotic docking. Bedside assistance can be provided by a 5-mm assistant port, which, if anticipated, is most efficiently placed prior to docking to allow direct visualization of the port placement. Unlike in adult laparoscopy, $5 \mathrm{~mm}$ ports are subject to herniation even in port sites as small as $3 \mathrm{~mm} .{ }^{38}$ Alternatively, a 14-gauge angiocatheter can be used as an assistant port, which has the capacity to introduce a $5 \mathrm{~F}$ ureteral catheter connected to suction, 2-mm cystoscopic graspers for tissue retraction, or cystoscopic scissors for suture cutting. ${ }^{39}$

Consideration of available instrumentation is important prior to planning the port placement. The Intuitive da Vinci $C$ does make 5-mm robotic ports with compatible instruments including scissors, needle drivers, graspers, and a monopolar 

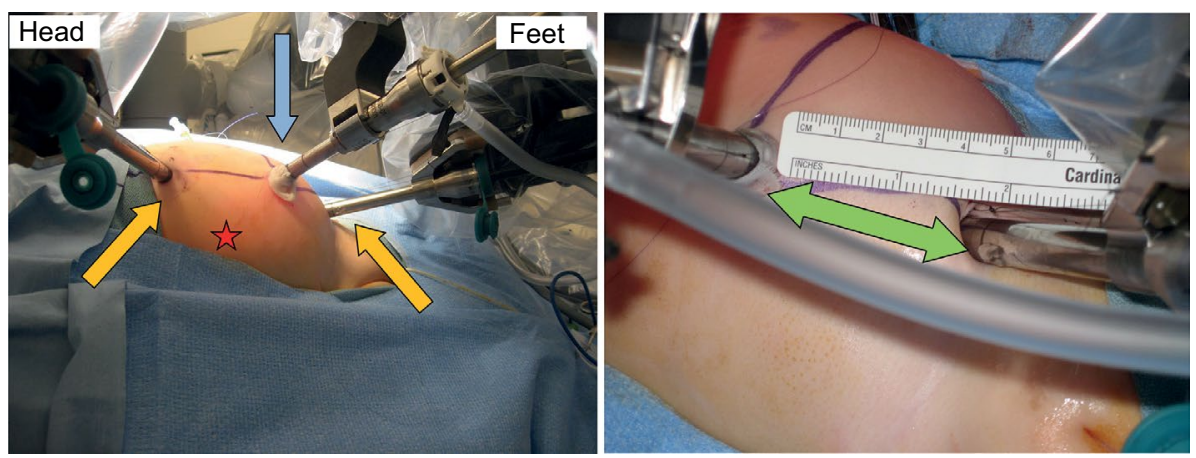

Figure 2 Port placement for robotic ureteroureterostomy.

Notes: The blue arrow indicates an umbilical $8.5-\mathrm{mm}$ camera port, the yellow arrows indicate 8-mm robotic surgeon ports, and the red star indicates the area of typical assistant port placement, if required. Note that the distance between ports is only $5 \mathrm{~cm}$, as indicated by the green arrows to the right.

hook. However, restrictions of the 5-mm instrumentation include lack of bipolar electrocautery and limitation of monopolar cautery to the hook instrument. Furthermore, the wristed motion of the 5 -mm instruments is more proximal than that of the 8-mm instruments, which may limit surgeon motion in situations where intracorporeal space is limited. For these reasons, using the 8-mm instruments was preferred, which allows for a greater selection of instrumentation including monopolar and bipolar cautery for a variety of instruments and fine needle drivers. Furthermore, 8-mm ports still result in a very acceptable postoperative cosmetic result (Figure 3).

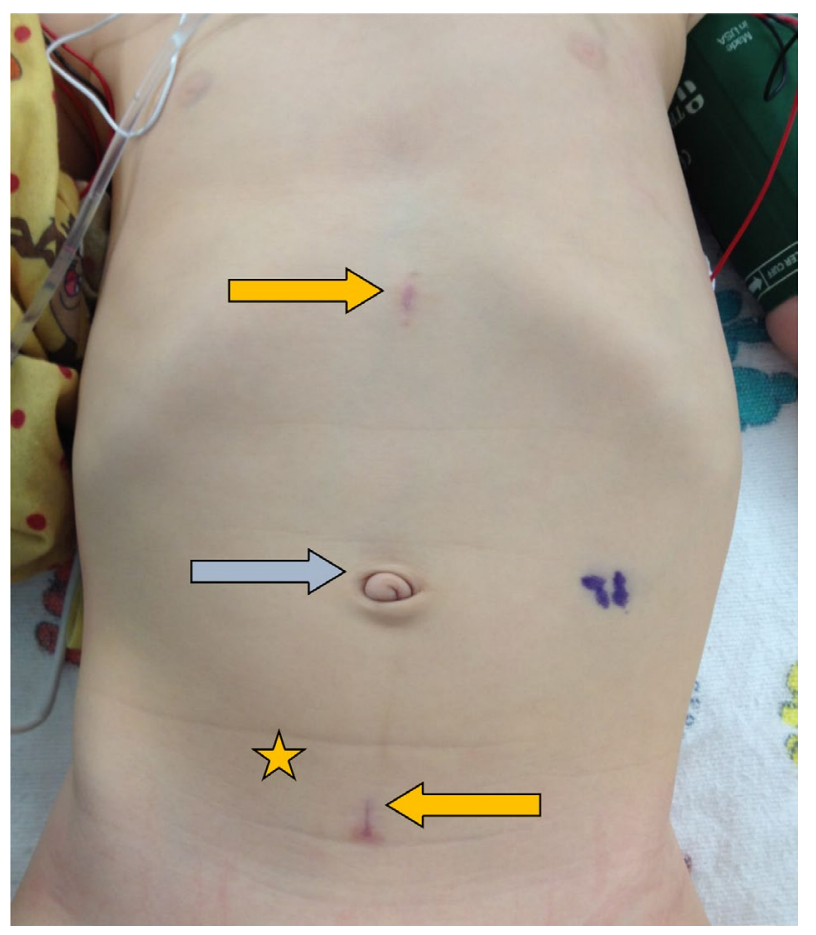

Figure 3 Healed 8-mm port sites noted by the yellow arrows and healed $8.5-\mathrm{mm}$ camera port noted by the blue arrow postoperatively. The yellow star indicates an alternative port site that may be required for smaller children. Note that the alternate port site crosses midline to the contralateral side to allow for adequate intracorporeal working space.
Following port placement, the patient is placed into Trendelenburg position, often while tilting the table laterally in order to allow the bowel to drop away from the area of interest at the pelvic brim. As the robotic docking may limit surgical movements to a single quadrant, laparoscopic dissection is sometimes undertaken prior to docking in order to ensure adequate definition of the operative field. Once the ureters are identified at the pelvic brim, the robot is docked over the patient's ipsilateral hip. The peritoneum is incised, and the donor ureter is first mobilized. If the child has suffered from UTIs, there is often a thick rind of tissue overlying the abnormal ureter. After sufficient dissection of the donor ureter, attention can then be turned to the recipient ureter. One must be certain of the ureteral anatomy prior to anastomosis, since an end-to-side anastomosis of the incorrect ureter could have devastating results. Often, the donor ureter, especially when obstructed or subject to severe VUR, is much more dilated than the recipient ureter, which aids in the identification of the correct ureter (Figure 4A). In addition, the identification of the stent within the recipient ureter further ensures a correct understanding of the anatomy prior to proceeding. The recipient ureter should undergo as minimal dissection as possible in order to ensure adequate blood supply and minimize iatrogenic damage to the healthy ureter. Furthermore, too much upward traction on the recipient ureter could dislodge the ureteral stent by pulling the distal end proximal to the ureterovesical junction. If the surgeon is concerned regarding the status of the distal end of the stent, intraoperative imaging should be obtained to confirm the stent placement. The donor ureter is transected at the area of the anticipated anastomosis. Transecting the donor ureter first enables the surgeon to assess the size required for the recipient ureter ureterotomy, which should be as long as the width of donor ureter. In order to allow an accurate incision, the ureterotomies are typically made with fine robotic Potts scissors. A thin ellipse of ureter is excised from the recipient ureterotomy 

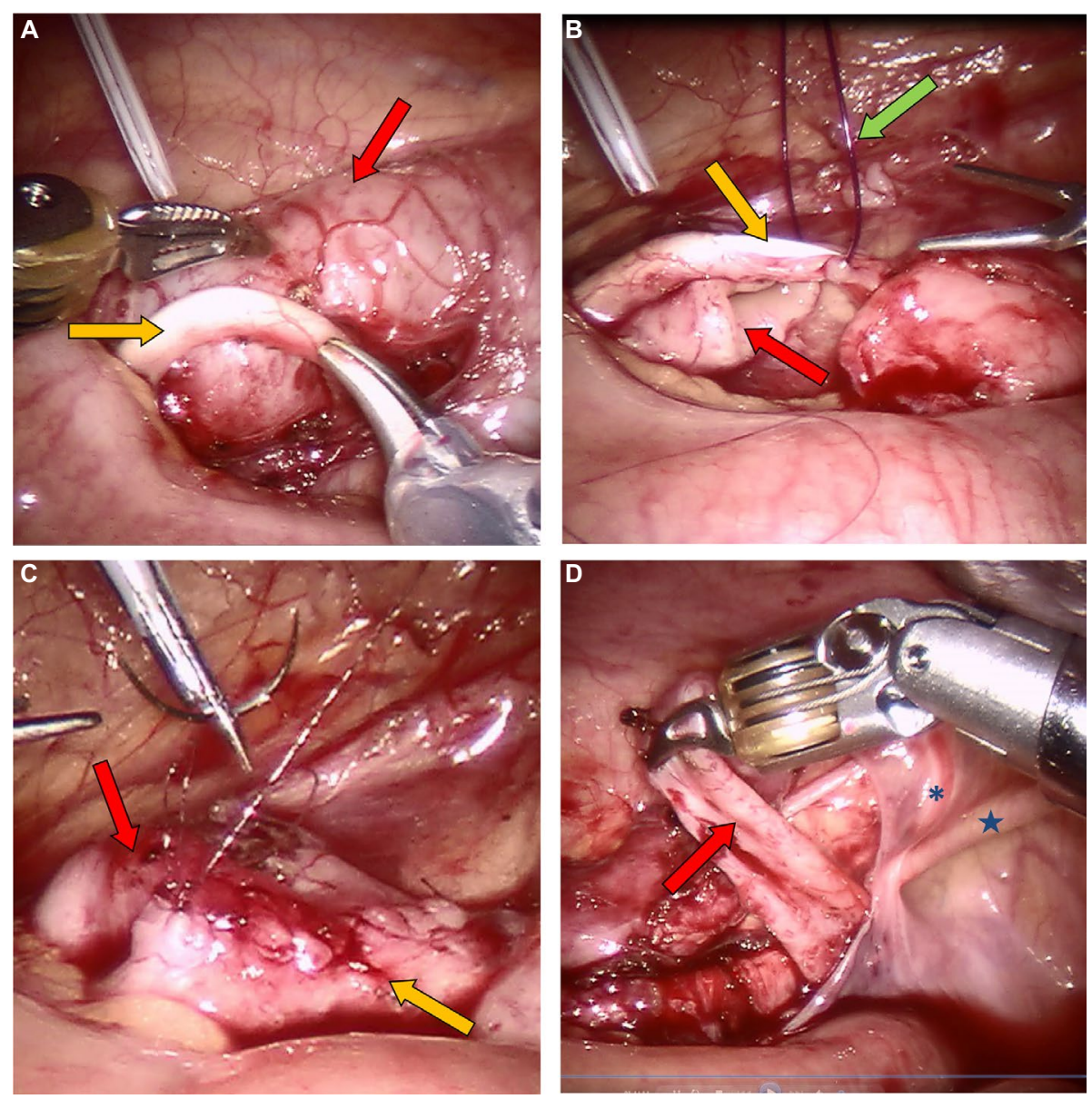

Figure 4 (A) Exposure of stented recipient ureter (orange arrow) and dilated, obstructed donor ureter (red arrow) at pelvic brim. (B) Transected donor ureter (red arrow) and spatulated recipient ureter (orange arrow) with hitch stitch for traction (green arrow). (C) Completed anastomosis of donor ureter (red arrow) and recipient ureter (yellow arrow) in an end-to-side fashion. (D) Exposure of distal obstructed ureteral stump (the red arrow) with visualization deep into the pelvis structures such as the vas.

to allow a wide enough opening for the anastomosis. After the ureters have been prepared, an end-to-side anastomosis is undertaken. We recommend transecting the donor obstructed upper pole ureter prior to opening the recipient because, once transected and decompressed, the upper pole ureter frequently retracts cephalad, thereby changing the anticipated insertion point on the recipient ureter (Figure 4B). Although there are a variety of strategies for the anastomosis, it was preferred to use monofilament dissolvable suture in a running fashion along the anterior and posterior edges of the anastomosis. Furthermore, 5-0 poliglecaprone for older children and 6-0 synthetic composite suture of glycolide, dioxanone, and trimethylene carbonate $\left(\right.$ Biosyn $^{\mathrm{TM}}$ ) for younger children were preferred. Importantly, the sutures should be dyed to allow adequate visibility for the surgeon (Figure 4C). For finer suturing, using the diamond-tipped needle drivers was preferred. Typically, the suture is cut to $12-14 \mathrm{~cm}$ to allow adequate length for each side of the anastomosis. Fastidious communication must be ensured during needle passage with the bedside assistant to ensure the needle is not lost during transfer. If required, a 2-0 polydioxanone suture on an $\mathrm{SH}$ needle that has been straightened (or "skied") can be placed percutaneously by the bedside assistant to allow for traction on the donor ureter during the anastomosis (hitch stitch).

One discernible intraoperative benefit of the robotic approach is improved pelvic visibility for the dissection of the distal ureteral stump. An aggressive approach toward the resection of the distal abnormal ureter must be weighed against the risks of a residual ureteral stump. ${ }^{40}$ In an open surgery, visibility in the deep pelvis may be limited. However, the robotic platform allows for improved visualization into the pelvis and a more accurate dissection of the distal ureteral stump (Figure 4D). ${ }^{41}$ This situation is somewhat analogous to the experience of robotic-assisted nephroureterectomy in the adult population. ${ }^{42}$ Therefore, distal dissection can be performed with care to avoid injury to the normal ureter as well as either Mullerian or Wolffian structures. However, an ectopic ureter into the bladder neck should be approached with caution, as extensive dissection could impair the continence mechanism at the level of the sphincter. Any 
remaining distal stump is oversewn in the case of reflux into that ureteral moiety or left open, if reflux is absent. If the system is obstructed, residual urine from the distal stump can be aspirated with suction.

Upon the completion of the case, the authors will typically instill aerosolized bupivacaine within the peritoneum for perioperative analgesia. ${ }^{43}$ Owing to the risk of port site hernia, all port sites are closed under a direct vision at the level of the fascia. ${ }^{38}$

\section{Postoperative course}

Patients were admitted to the general care floor for observation postoperatively. Care of postoperative upper tract reconstruction has been standardized at the institution. All the patients received around-the-clock oral acetaminophen and ketorolac once urine output was adequate $(>1 \mathrm{~mL} / \mathrm{kg} / \mathrm{h})$, with the goal of minimizing postoperative narcotic utilization. In addition, all the patients also received stool softeners and/or laxatives to minimize constipation postoperatively. A Foley catheter was left for drainage, for typically 1-2 days postoperatively. Once the catheter was removed, the patients were instructed to perform timed voiding in order to minimize urine holding patterns. Recognizing the presence of lower urinary tract symptoms preoperatively is important to optimize postoperative bladder hygiene. The presence of preoperative lower urinary tract symptoms has been associated with a higher risk of early postoperative complications in a population of children undergoing stented pyeloplasty, and extrapolating this to other upper tract reconstruction, the presence of a ureteral stent associated with underlying voiding dysfunction may lead to a reflux of urine across the ureterovesical junction and additional strain on the anastomosis. ${ }^{44}$

Following discharge, the patients returned for a removal of the ureteral stent under general anesthetic in 2-4 weeks. Antibiotic prophylaxis was typically not used as no data supported the use of antibiotic prophylaxis in children with indwelling ureteral stents. ${ }^{45}$ The first postoperative ultrasound was typically obtained $\sim-6$ weeks following stent removal, and the authors preferred to follow the patients every 6-12 months with renal ultrasonography thereafter.

\section{Complications of ureteroureterostomy}

Complications of ureteroureterostomy can include complications at the anastomosis, injury to the lower pole ureter or nearby structures, and risks of the retained ureteral stump. As with any anastomosis, urine leak can occur; however, this may be minimized by ureteral stenting. Although robotic pyeloplasty has been described without ureteral stents, the authors were unaware of any such data investigating a stentless approach in RUU. ${ }^{46}$ Regardless of the use of a ureteral stent, certain surgical principles must be maintained to minimize the risk of urine leak. Adequate dissection of the obstructed upper pole ureter can minimize tension, allowing for a tension-free anastomosis. Furthermore, adequate mucosal approximation to achieve a watertight anastomosis is of paramount importance. Salient to the concept of ureteral stenting, the presence of a ureteral stent across the ureterovesical junction will allow reflux of urine across the anastomosis in an otherwise nonrefluxing system. Therefore, the authors believed that screening for and managing any bowel-bladder dysfunction in the older population, typically with a focused history detailing bladder and bowel habits and episodes of incontinence, are important to reduce the risk of postoperative urine holding, which may place pressure on the anastomosis. Urine leak following transperitoneal RUU will likely present with as an ileus, with abdominal pain, nausea, and vomiting caused by peritoneal irritation from urine. ${ }^{47}$ Creatinine may be elevated if there is an abundance of intra-abdominal urine, indicating peritoneal resorption. Ultrasound may reveal an urinoma or fluid collection around the site of the anastomosis but may also just reveal free fluid in early manifestations of leak. Although excretory urography with computed tomography, intravenous urography, or retrograde pyelography may reveal a urine leak, often the clinical setting of ileus and ultrasound findings of free fluid or an urinoma can guide management, including maximal bladder decompression with a Foley catheter. If the condition of the patient does not improve or the patient has severe presentation, percutaneous nephrostomy could be considered; however, one must be cognizant of the relevant anatomy in choosing which of the renal moieties, if not both, should be drained. Reoperation could be considered in the setting of failed drainage.

Stricture could develop at the site of the anastomosis in the setting of devascularization of the upper or lower pole segment. Careful tissue handling and judicious use of electrocautery will help to minimize this complication as well as ensuring that the anastomosis is not under any tension. Stricture may present with increasing hydronephrosis, pain, or UTI in the follow-up. Ultrasonography may show hydroureter to the anticipated point of the anastomosis, and an NM renogram can demonstrate poor drainage curves. However, definitive assessment of the narrowing should be evaluated with a retrograde pyelogram. Importantly, if stricture develops at the $\mathrm{Y}$ anastomosis, both upper and lower pole moieties may be placed at risk. Some debates exist over if ureteral size 
discrepancy, as defined by a donor ureteral diameter $>2$ times the diameter of the recipient ureter, impacts success rates. Although ureteral size discrepancy has been noted in many series of open ureteroureterostomy, there does not seem to be an impact on success rates, provided that the ureterotomy on the recipient ureter is wide enough to accommodate the entire diameter of the donor ureter. ${ }^{9,29,48,49}$

Complications related to the retained ureteral stump following upper tract management of duplicated collecting systems are well documented and may be a future source for infection or rarely pain. The data mostly from upper pole heminephrectomy series suggested up to a $10 \%$ risk of complications from the ureteral stump. ${ }^{50,51}$ Typically, a refluxing stump will be oversewn while a nonrefluxing stump will be left open, so as not to create an iatrogenically closed system. Efforts to reduce the complications of the distal stump include resection as far distal as technically feasible. However, the risks of complete ureteral resection may outweigh the risks of a retained ureteral stump. ${ }^{40}$ Importantly, the common sheath of the duplicated ureters involves the distal 2-3 cm of each ureter; however, this may vary in widely ectopic ureters. ${ }^{9}$ As such, dissection into this area during surgical excision places the normal lower pole ureter at risk. One strategy to mitigate this risk is to resect as much stump as feasible, while leaving the back wall of the abnormal ureteral stump on the common sheath, in an effort not to disrupt the common sheath blood supply.

\section{Outcomes}

To the authors' knowledge, 5 series of RUU have been published in the pediatric literature with a total of 47 patients. ${ }^{41,52-55}$ Passerotti et al published the first case series in 2008, including 3 patients with proximal ureteral strictures in nonduplicated systems. ${ }^{54}$ Leavitt et al published the first series of children undergoing ipsilateral RUU for ureteral duplication with obstruction. ${ }^{52}$ Table 1 summarizes the published experience to date with robotic-assisted ureteroureterostomy, in both primary ureteroureterostomy and ipsilateral ureteroureterostomy for duplicated systems. For series that report RUU for duplication, assistant ports were not typically utilized. The sizes of the robotic ports ( $5 \mathrm{vs} 8 \mathrm{~mm}$ ) were surgeon-dependent. Biles et al performed the anastomosis proximally, either to the unaffected renal pelvis or just off the lower pole of the kidney. ${ }^{41}$ Meanwhile, Leavitt et al utilized a more distal approach, and the approach was similar to that reported by Lee et al. ${ }^{52,53}$

In the institutional experience, with a total of 24 patients over an 8-year period, the results were similar to those of the published studies, with comparable operative times and length of stay. Median follow-up in this series was 16 months. Two patients experienced postoperative UTI, one of which was a pyelonephritis requiring readmission, and one patient with a ureteral structure undergoing a primary ureteroureterostomy required a revision open ureteroureterostomy due to a recurrent stricture $\sim 1$ year following the initial procedure that was deemed too long for an endoscopic treatment. This patient has a solitary kidney and renal function returned to baseline following reoperation. A second patient required open revision of the upper to lower pole ureteroureterostomy owing to the obstruction at the anastomosis within the first month of surgery. Both the patients had complications that impacted both the upper and lower pole moieties of the diseased kidney.

As noted above, the short-term outcomes for RUU in the pediatric population are promising. Comparisons to an open approach are limited due to issues with selection bias and surgeon experience. However, Lee et al compared open

Table I Summary of robotic-assisted ureteroureterostomy series published in the pediatric literature

\begin{tabular}{|c|c|c|c|c|c|c|c|}
\hline Author & $\mathbf{N}$ & Age (mean) & Indications & LOS (days) & OR Time (min) & Complications & Follow-up (months) \\
\hline \multicolumn{8}{|c|}{ Proximal Ureteral Stricture } \\
\hline Passerioti $^{54}$ & 3 & 9.4 years & Proximal ureteral stricture (3) & 3.5 & 244 & None & 11.6 \\
\hline Smith $^{55}$ & 2 & 8 years & $\begin{array}{l}\text { Vascular obstruction of the } \\
\text { proximal ureter (2) }\end{array}$ & 1.3 & 283 & None & 1 \\
\hline \multicolumn{8}{|c|}{ Duplicated Ureteral System } \\
\hline \multirow[t]{3}{*}{ Leavitt $^{52}$} & 5 & 61 months & Ureterocele (I) & 1.2 & 225 & Pyelonephritis (I) & 10 \\
\hline & & & Ectopic Ureter (I) & & & & \\
\hline & & & Unspecified (3) & & & & \\
\hline \multirow[t]{3}{*}{$\mathrm{Lee}^{53}$} & 25 & 6.1 years & Ureterocele (3) & 1.6 & 186 & UTI (4) & 16.4 \\
\hline & & & Ectopic ureter (I8) & & & & \\
\hline & & & Stricture (4) & & & & \\
\hline \multirow[t]{2}{*}{ Biles $^{41}$} & 12 & 19.4 months & Ectopic ureter (12) & 2.1 & 167 & Upper respiratory & 3 \\
\hline & & & & & & infection (I) & \\
\hline \multirow[t]{2}{*}{ Lendvay* } & 24 & 5.4 years & Ectopic ureter (I7) VUR (2) & 1.9 & 183 & UTI (2) & 16 \\
\hline & & & Stricture (2) Ureterocele (3) & & & Obstruction (2) & \\
\hline
\end{tabular}

Note: *Lendvay unpublished series.

Abbreviations: LOS, length of stay; OR, operating room; VUR, vesicoureteral reflux; UTI, urinary tract infection. 
and robotic approaches and found no significant differences in operative time or complication rates. ${ }^{53}$ In other series, the length of stay was comparable to what would be expected in open cases, and operative times were reasonable, if a bit longer, than that in the standard open approaches. However, only one series presented a follow-up time $>1$ year, and these series are from experienced pediatric robotic surgeons, which may limit the generalizability across other centers.

\section{Future directions}

Currently, RUU has been demonstrated to be safe and effective in short-term management of symptomatic ureteral duplication. However, as with all the new technologies and techniques, there remains a lack of intermediate or long-term outcomes. As robotic-assisted tissue handling does differ from that of open surgery, it is important to document the long-term durability of the repair. In addition, RUU has the theoretical benefit of improved management of the distal ureteral stump, and the rates of symptomatic ureteral stump infections or pain should be assessed to demonstrate this benefit. Although gold standard assessment would be a prospective randomized comparison to an open approach, this study would be difficult to perform given the low numbers of patients requiring ureteroureterostomy. However, surgeons should be encouraged to monitor their own outcomes with the hopes of validating this technique on a wider scale.

Cost containment remains a major concern in the current health-care environment. ${ }^{56}$ Robotic surgery is a cost-intensive technology and may not be cost-effective in the current health-care environment. ${ }^{57}$ In pediatric hospitals, the costs of robotic surgery-associated hospitalizations are equal as compared to nonrobotic correlates. ${ }^{58}$ Owing to high fixed costs, the cost per patient for robotic surgery is volume dependent. Furthermore, robotic surgery may become cost-effective if the length of stay is substantially reduced over the standard open approach..$^{59}$ Many young children undergoing open ureteroureterostomy may only stay 1 full hospital day, and the open approach has even been reported as an outpatient procedure. ${ }^{18}$ To the authors' knowledge, a specific cost analysis for RUU in children has not been performed. Importantly, this analysis would likely reveal RUU to be more costly than the open correlate at present. However, costs of robotic surgery may decrease as additional robotic manufacturers enter the marketplace. ${ }^{60}$

Debate currently exists as to the appropriateness of the robotic platform for a number of pediatric procedures. Robotic-assisted pyeloplasty has been shown to have consistently shorter hospital stays and comparable success rates to open surgery and has rapidly been adopted in the pediatric population. ${ }^{61,62}$ Although additional costs are a concern, the short-term outcomes of this procedure are well accepted. ${ }^{62}$ However, robotic-assisted ureteral reimplantation has been brought under higher scrutiny for concerns of high complications, lower success rates, and higher costs, as compared to open ureteral reimplantation. ${ }^{63,64}$ Early results in RUU are promising. However, there is likely a demographic "sweet spot" in which certain patients (ie, older and obese) may derive greater benefit from the minimally invasive approach. Defining these characteristics will be important not only for RUU but also across all types of robotic-assisted pediatric urological surgery.

\section{Conclusion}

Ipsilateral ureteroureterostomy is a well-accepted treatment modality for duplicated collecting systems associated with either symptomatic VUR or obstruction. The robotic-assisted platform offers the surgeon the improved management of the distal ureteral stump, in addition to providing the typical benefits of a minimally invasive approach. Patient selection for RUU is similar to that for an open ureteroureterostomy; however, older children may derive more benefit from minimally invasive surgery. The early outcomes of RUU are promising, and future studies necessary to validate the longer-term results in a prospective fashion.

\section{Disclosure}

Dr Ellison reports no conflicts of interest to disclose. Dr Lendvay is a Chief Medical Officer, cofounder, board member, and equity owner of CSATS Inc. This interest does not have any conflict with the current research.

\section{References}

1. Privett J, Jeans W, Roylance J. The incidence and importance of renal duplication. Clin Radiol. 1976;27(4):521-530.

2. Meyer R. Normal and abnormal development of the ureter in the human embryo - a mechanistic consideration. Anat Rec. 1946;96(4):355-371.

3. Slaughenhoupt BL, Mitcheson HD, Lee DL. Ureteral duplication with lower pole ectopia to the vas: a case report of an exception to the Weigert-Meyer law. Urology. 1997;49(2):269-271.

4. Jain P, Parelkar S, Shah H, Sanghavi B, Mishra P. Uncrossed complete ureteral duplication with dysplastic lower moiety: a violation of the Weigert-Meyer law. J Pediat Urol. 2008;4(5):404-406.

5. Pantuck A, Barone J, Rosenfeld D, Fleisher M. Occult bilateral ectopic vaginal ureters causing urinary incontinence: diagnosis by computed tomography. Abdom Imaging. 1996;21(1):78-80.

6. Chacko JK, Koyle MA, Mingin GC, Furness PD. Ipsilateral ureteroureterostomy in the surgical management of the severely dilated ureter in ureteral duplication. J Urology. 2007;178(4):1689-1692.

7. Ewalt D, Glenski W, Bernier P. Ureterocele associated with ureteral duplication and a nonfunctioning upper pole segment: management by partial nephroureterectomy alone. J Urol. 1995;154(2):723-726. 
8. Peters CA, Skoog SJ, Arant BS, et al. Summary of the AUA guideline on management of primary vesicoureteral reflux in children. $J$ Urol. 2010;184(3):1134-1144.

9. Lashley DB, McAleer IM, Kaplan GW. Ipsilateral ureteroureterostomy for the treatment of vesicoureteral reflux or obstruction associated with complete ureteral duplication. J Urol. 2001;165(2):552-554.

10. Casale P, Kojima Y. Robotic-assisted laparoscopic surgery in pediatric urology: an update. Scand J Surg. 2009;98(2):110-119.

11. Kutikov A, Nguyen M, Guzzo T, Canter D, Casale P. Laparoscopic and robotic complex upper-tract reconstruction in children with a duplex collecting system. J Endourol. 2007;21(6):621-624.

12. Yates DR, Vaessen C, Roupret M. From Leonardo to da Vinci: the history of robot-assisted surgery in urology. BJU Int. 2011;108(11):1708-1714.

13. Lanfranco AR, Castellanos AE, Desai JP, Meyers WC. Robotic surgery: a current perspective. Ann Surg. 2004;239(1):14-21.

14. Howe A, Kozel Z, Palmer L. Robotic surgery in pediatric urology. Asian J Urol. 2017;4(1):55-67.

15. Nguyen HT, Herndon CA, Cooper C, et al. The Society for Fetal Urology consensus statement on the evaluation and management of antenatal hydronephrosis. J Pediatr Urol. 2010;6(3):212-231.

16. Passerotti CC, Nguyen HT, Eisner BH, Lee RS, Peters CA. Laparoscopic reoperative pediatric pyeloplasty with robotic assistance. J Endourol. 2007;21(10):1137-1140.

17. van Goor H. Consequences and complications of peritoneal adhesions. Colorectal Dis. 2007;9(Suppl 2):25-34.

18. Prieto J, Ziada A, Baker L, Snodgrass W. Ureteroureterostomy via inguinal incision for ectopic ureters and ureteroceles without ipsilateral lower pole reflux. J Urol. 2009;181(4):1844-1850.

19. Staatz G, Rohrmann D, Nolte-Ernsting CA, et al. Magnetic resonance urography in children: evaluation of suspected ureteral ectopia in duplex systems. J Urol. 2001;166(6):2346-2350.

20. Adeb M, Darge K, Dillman JR, Carr M, Epelman M. Magnetic resonance urography in evaluation of duplicated renal collecting systems. Magn Reson Imaging Clin N Am. 2013;21(4):717-730.

21. Merguerian PA, Taenzer A, Knoerlein K, McQuiston L, Herz D. Variation in management of duplex system intravesical ureteroceles: a survey of pediatric urologists. J Urol. 2010;184(4):1625-1630.

22. Han MY, Gibbons MD, Belman AB, Pohl HG, Majd M, Rushton HG. Indications for nonoperative management of ureteroceles. $J$ Urol. 2005;174(4):1652-1656.

23. Byun E, Merguerian PA. A meta-analysis of surgical practice patterns in the endoscopic management of ureteroceles. J Urol. 2006; 176(4):1871-1877.

24. Jayanthi VR, Koff SA. Long-term outcome of transurethral puncture of ectopic ureteroceles: initial success and late problems. J Urol. 1999; 162(3):1077-1080.

25. Ellsworth P, Lim D, Walker R, Stevens P, Barraza M, Mesrobian HG. Common sheath reimplantation yields excellent results in the treatment of vesicoureteral reflux in duplicated collecting systems. J Urol. 1996;155(4):1407-1409.

26. Joyeux L, Lacreuse I, Schneider A, et al. Long-term functional renal outcomes after retroperitoneoscopic upper pole heminephrectomy for duplex kidney in children: a multicenter cohort study. Surg Endosc. 2017;31(3): 1241-1249.

27. Jayram G, Roberts J, Hernandez A, et al. Outcomes and fate of the remnant moiety following laparoscopic heminephrectomy for duplex kidney: a multicenter review. J Pediatr Urol. 2011;7(3):272-275.

28. Romao R, Figueroa V, Salle JP, Koyle M, Bägli D, Lorenzo A. Laparoscopic ureteral ligation (clipping): a novel, simple procedure for pediatric urinary incontinence due to ectopic ureters associated with non-functioning upper pole renal moieties. J Pediatr Urol. 2014;10(6): 1089-1094.

29. Jelloul L, Valayer J. Ureteroureteral anastomosis in the treatment of reflux associated with ureteral duplication. J Urol. 1997;157(5):1863-1865.

30. Estrada CR, Passerotti CC, Graham DA, et al. Nomograms for predicting annual resolution rate of primary vesicoureteral reflux: results from 2,462 children. J Urol. 2009;182(4):1535-1541.
31. Husmann D, Allen T. Resolution of vesicoureteral reflux in completely duplicated systems: fact or fiction? J Urol. 1991;145(5):1022-1023.

32. Perez-Brayfield M, Kirsch AJ, Hensle TW, Koyle MA, Furness P, Scherz HC. Endoscopic treatment with dextranomer/hyaluronic acid for complex cases of vesicoureteral reflux. J Urol. 2004;172(4):1614-1616.

33. Miyakita H, Ninan G, Puri P. Endoscopic correction of vesico-ureteric reflux in duplex systems. Eur Urol. 1993;24(1):111-115.

34. Bockrath J, Maizels M, Firlit C. The use of lower ipsilateral ureteroureterostomy to treat vesicoureteral reflux or obstruction in children with duplex ureters. J Urol. 1983;129(3):543-544.

35. Chitwood WR, Nifong LW, Chapman WH, et al. Robotic surgical training in an academic institution. Ann Surg. 2001;234(4):475-486.

36. Peters CA. Complications in pediatric urological laparoscopy: results of a survey. J Urol. 1996;155(3):1070-1073.

37. Finkelstein J, Levy A, Silva M, Murray L, Delaney C, Casale P. How to decide which infant can have robotic surgery? Just do the math. $J$ Pediatr Urol. 2015;11(4):170. e1-170. e4.

38. Yee DS, Duel BP. Omental herniation through a 3-mm umbilical trocar site. J Endourol. 2006;20(2):133-134.

39. Hotaling JM, Shear S, Lendvay TS. 14-gauge angiocatheter: the assist port. J Laparoendosc Adv Surg Tech A. 2009;19(5):699-701.

40. Ade-Ajayi N, Wilcox D, Duffy P, Ransley P. Upper pole heminephrectomy: is complete ureterectomy necessary? BJU Int. 2001;88(1):77-79.

41. Biles MJ, Finkelstein JB, Silva MV, Lambert SM, Casale P. Innovation in robotics and pediatric urology: robotic ureteroureterostomy for duplex systems with ureteral ectopia. J Endourol. 2016;30(10):1041-1048.

42. Pugh J, Parekattil S, Willis D, Stifelman M, Hemal A, Su LM. Perioperative outcomes of robot-assisted nephroureterectomy for upper urinary tract urothelial carcinoma: a multi-institutional series. BJU Int. 2013;112(4):E295-E300.

43. Freilich D, Houck C, Meier P, Passerotti C, Retik A, Nguyen H. The effectiveness of aerosolized intraperitoneal bupivacaine in reducing postoperative pain in children undergoing robotic-assisted laparoscopic pyeloplasty. J Pediatr Urol. 2008;4(5):337-340.

44. Chrzan R, Panek W, Kuijper C, et al. Short Term Complications after Pyeloplasty in Children with Lower Urinary Tract Anomalies. Urology. 2017;100:195-202.

45. Ferroni MC, Lyon TD, Rycyna KJ, et al. The role of prophylactic antibiotics after minimally invasive pyeloplasty with ureteral stent placement in children. Urology. 2016;89:107-112.

46. Silva MV, Levy AC, Finkelstein JB, Van Batavia JP, Casale P. Is perioperative urethral catheter drainage enough? The case for stentless pediatric robotic pyeloplasty. J Pediatr Urol. 2015;11(4):175. e1-175. e5.

47. Jarrett TW, Chan DY, Charambura TC, Fugita O, Kavoussi LR. Laparoscopic pyeloplasty: the first 100 cases. J Urol. 2002;167(3):1253-1256.

48. McLeod D, Alpert S, Ural Z, Jayanthi V. Ureteroureterostomy irrespective of ureteral size or upper pole function: a single center experience. J Pediatr Urol. 2014;10(4):616-619.

49. Huisman T, Kaplan G, Brock W, Packer M. Ipsilateral ureteroureterostomy and pyeloureterostomy: a review of 15 years of experience with 25 patients. J Urol. 1987;138(5):1207-1210.

50. Cain MP, Pope JC, Casale AJ, Adams MC, Keating MA, Rink RC. Natural history of refluxing distal ureteral stumps after nephrectomy and partial ureterectomy for vesicoureteral reflux. J Urol. 1998;160(3): 1026-1027.

51. Caluwé D, Chertin B, Puri P. Long-term outcome of the retained ureteral stump after lower pole heminephrectomy in duplex kidneys. Eur Urol. 2002;42(1):63-66.

52. Leavitt DA, Rambachan A, Haberman K, DeMarco R, Shukla AR. Robot-assisted laparoscopic ipsilateral ureteroureterostomy for ectopic ureters in children: description of technique. J Endourol. 2012;26(10): 1279-1283.

53. Lee NG, Corbett ST, Cobb K, Bailey GC, Burns AS, Peters CA. BiInstitutional comparison of robot-assisted laparoscopic versus open ureteroureterostomy in the pediatric population. J Endourol. 2015;29(11): 1237-1241. 
54. Passerotti CC, Diamond DA, Borer JG, Eisner BH, Barrisford G, Nguyen HT. Robot-assisted laparoscopic ureteroureterostomy: description of technique. J Endourol. 2008;22(4):581-586.

55. Smith K, Shrivastava D, Ravish I, Nerli R, Shukla A. Robot-assisted laparoscopic ureteroureterostomy for proximal ureteral obstructions in children. J Pediatr Urol. 2009;5(6):475-479.

56. Fuchs VR. The gross domestic product and health care spending. NEngl J Med. 2013;369(2):107-109.

57. Barbash GI, Glied SA. New technology and health care costs - the case of robot-assisted surgery. $N$ Engl J Med. 2010;363(8):701-704.

58. Mahida JB, Cooper JN, Herz D, et al. Utilization and costs associated with robotic surgery in children. J Surg Res. 2015;199(1): 169-176.

59. Leddy LS, Lendvay TS, Satava RM. Robotic surgery: applications and cost effectiveness. Open Access Surg. 2010;3:99-107.
60. Hoffman, A.N. (2010). Intuitive Surgical, Inc.: How Long Can Their Monopoly Last?. RSM Case Development Centre. Retrieved from http:// hdl.handle.net/1765/38794. Accessed April 20, 2017.

61. Minnillo BJ, Cruz JA, Sayao RH, et al. Long-term experience and outcomes of robotic assisted laparoscopic pyeloplasty in children and young adults. J Urol. 2011;185(4):1455-1460.

62. Varda BK, Johnson EK, Clark C, Chung BI, Nelson CP, Chang SL. National trends of perioperative outcomes and costs for open, laparoscopic and robotic pediatric pyeloplasty. J Urol. 2014;191(4):1090-1096.

63. Grimsby GM, Dwyer ME, Jacobs MA, et al. Multi-institutional review of outcomes of robot-assisted laparoscopic extravesical ureteral reimplantation. J Urol. 2015;193(5):1791-1795.

64. Kurtz MP, Leow JJ, Varda BK, et al. Robotic versus open pediatric ureteral reimplantation: Costs and complications from a nationwide sample. J Pediatr Urol. 2016;12(6):408.e1-408.e6.
Robotic Surgery: Research and Reviews

\section{Publish your work in this journal}

Robotic Surgery: Research and Reviews is an international, peer reviewed open access, online journal publishing original research, commentaries, reports, and reviews on the theory, use and application of robotics in surgical interventions. Articles on the use of supervisory-controlled robotic systems, telesurgical devices, and shared-control systems are

\section{Dovepress}

invited. The manuscript management system is completely online and includes a very quick and fair peer review system, which is all easy to use. Visit http://www.dovepress.com/testimonials.php to read real quotes from published authors. 